\title{
COMPARISON OF 2 DIFFERENT DOSES OF ORAL PREGABALIN AS PREMEDICATION ON HAEMODYNAMIC PRESSOR RESPONSE DURING INTUBATION AND EXTUBATION IN MODIFIED RADICAL MASTECTOMY PATIENTS
}

\author{
Nidhi Rani Gupta1, Deepa George ${ }^{2}$ \\ ${ }^{1}$ Lecturer, Department of Anaesthesia, Government T. D. Medical College, Alappuzha. \\ ${ }^{2}$ Assistant Professor, Department of Anaesthesia, Government T. D. Medical College, Alappuzha.
}

\section{ABSTRACT}

\section{BACKGROUND}

Intubation and extubation processes are associated with significant haemodynamic response, thus making adequate premedication a necessity. Our study compared 2 doses of oral pregabalin as premedication for blunting this haemodynamic response during intubation and extubation in patients undergoing modified radical mastectomy.

\section{MATERIALS AND METHODS}

A prospective observational study was carried out in adult female patients in the age group of 24-60 years undergoing modified radical mastectomy. A total of 90 patients were selected. Those who received oral placebo were placed in group I, those who received oral pregabalin $150 \mathrm{mg}$ were placed in group II and those who received oral pregabalin $300 \mathrm{mg}$ were placed in group III. The 3 groups were assessed for pre-operative sedation, haemodynamic changes from baseline to before and after intubation $(0$ min.), $5 \mathrm{~min}$., $10 \mathrm{~min}$. and before and after extubation ( $0 \mathrm{~min}$.), $5 \mathrm{~min}$., $10 \mathrm{~min}$. Data analysis was done by ANOVA, independent $\mathrm{T}$ and Chi square test and statistical analysis was done using SPSS version 21.0.

\section{RESULTS}

Pre-operative sedation score was higher in both pregabalin groups. Statistically significant attenuation of mean arterial pressure and heart rate was seen in group II and III during and after intubation and extubation. No significant difference in blunting of haemodynamic response between $150 \mathrm{mg}$ and $300 \mathrm{mg}$ pregabalin premedication groups.

\section{CONCLUSION}

Pregabalin $150 \mathrm{mg}$ and Pregabalin $300 \mathrm{mg}$ as oral premedication were effective and safe in blunting of haemodynamic response to intubation and extubation without significant side effects in patients undergoing Modified Radical Mastectomy.

\section{KEYWORDS}

Haemodynamic Response, Intubation, Extubation, Pregabalin, Modified Radical Mastectomy (MRM).

HOW TO CITE THIS ARTICLE: Gupta NR, George D. Comparison of 2 different doses of oral pregabalin as premedication on haemodynamic pressor response during intubation and extubation in modified radical mastectomy patients. J. Evolution Med. Dent. Sci. 2017;6(44):3419-3423, DOI: 10.14260/Jemds/2017/741

\section{BACKGROUND \\ Haemodynamic response to intubation and extubation is a well-known complication in administration of general anaesthesia.[1] These responses may increase morbidity or mortality especially in patients having other comorbid conditions. Many techniques were evaluated for blunting of this response such as deepening of plane of anaesthesia, pre- treatment with vasodilators, adrenoceptor blocker, calcium channel blockers and opioids.[2,3] However, there is no general consensus about particular drug for this. Many studies have evaluated the use of pregabalin as a post- operative analgesic, ${ }^{[4]}$ but to our knowledge no study has been done to evaluate the use of oral pregabalin for blunting}

Financial or Other, Competing Interest: None.

Submission 25-04-2017, Peer Review 19-05-2017,

Acceptance 25-05-2017, Published 01-06-2017.

Corresponding Author:

Dr Nidhi Rani Gupta,

Lecturer,

Department of Anaesthesia,

Government T. D. Medical College,

J Block, 3rd Floor, Alappuzha-688005,

Kerala.

E-mail: drnidhigarg@gmail.com

DOI: $10.14260 /$ jemds $/ 2017 / 741$ of haemodynamic response to intubation and extubation in patients undergoing modified radical mastectomy. The aim of our study was to compare the 2 doses of oral pregabalin as premedication for blunting of this pressor response.

Pregabalin, is expressed structurally as (S)-3 aminomethyl-5-methylhexanoic acid. It is structurally related to the inhibitory neurotransmitter gamma-aminobutyric acid (GABA), but is not functionally related to it. It modulates or decreases the release of excitatory neurotransmitters such as glutamate, norepinephrine, etc. and return the neurons to normal state from overexcited state. It also has anti-anxiety, anticonvulsant and analgesic properties and prevents the neuropathic component of acute nociceptive pain of surgery.[5] It is well absorbed and tolerated after oral administration, with peak plasma concentrations occurring within $1 \mathrm{hr}$. It undergoes negligible hepatic metabolism. It is non-narcotic, exhibits no effect on opioid, serotonin, DOPA receptors or cyclooxygenase inhibiting activity but produces clinically important reduction in pain scores.

Our study compared the efficacy and safety of two doses of oral pregabalin premedication for blunting of haemodynamic response to intubation and extubation in patients undergoing modified radical mastectomy. 


\section{MATERIALS AND METHODS}

The prospective observational study consisted of 90 normotensive consented adult female patients aged 24-60 years of ASA physical status I and II undergoing Modified Radical Mastectomy for CA Breast under general anaesthesia. The study was carried out from July 2016 to March 2017 after approval by ethical committee. Patients were allocated into 3 equal groups. Group I had received placebo, Group II had received pregabalin $150 \mathrm{mg}$ and Group III had received pregabalin $300 \mathrm{mg}$ orally with sips of water about $1 \mathrm{hr}$. before planned surgery. Patients with H/o allergy to any drug, cardiac, pulmonary or renal disease, obesity, anticipated difficult intubation, laryngoscopy exceeding 20 seconds, second attempt for intubation, patients on sedatives, hypnotics and analgesics for chronic pain were excluded from the study.

Detailed pre-anaesthetic evaluation was done for every patient. After shifting the patient to operation table, monitors were attached and baseline heart rate, mean arterial blood pressure were recorded. The preoperative sedation score was assessed by the Ramsay sedation scale: 1- anxious, agitated or restless; 2- co-operative, oriented and tranquil; 3responds to command; 4- asleep with brisk response to stimulus; 5- asleep with sluggish response to stimulus; 6asleep with no response.[6] After securing IV access, Inj. Fentanyl 2 microgram $/ \mathrm{kg}$ was administered to all patients and induction was done with inj. Propofol $1.5-2 \mathrm{mg} / \mathrm{kg}$ till abolition of eyelash reflex, ventilation checked, Inj. Succinylcholine $2 \mathrm{mg} / \mathrm{kg}$ was given and tracheal intubation performed after 60 seconds by faculty anaesthesiologist having at least 5 years' experience. Till $10 \mathrm{~min}$. haemodynamics were monitored and no surgical intervention and change in positioning of patient was not done in that time. ${ }^{[7,8]}$

Anaesthesia was maintained with $30 \%$ oxygen $+60 \%$ nitrous oxide +inj. propofol infusion @ 50-70 microgram $/ \mathrm{kg} / \mathrm{min}$. (According to haemodynamics) + inj. Vecuronium $0.08 \mathrm{mg} / \mathrm{kg}$ then $1 / 5$ of initial dose. Haemodynamics were recorded at $0,5,10 \mathrm{~min}$. by other faculty and if any untoward haemodynamic derangement occurred was managed subsequently like symptomatic bradycardia with atropine and hypotension with IV fluids and vasoactive drugs. Thus, anaesthesia process and surgery too i.e. MRM was same for every patient in the study to avoid bias. All patients were monitored intraoperatively and after surgery was over, patients were reversed with inj. neostigmine $(0.05 \mathrm{mg} / \mathrm{kg})$ and glycopyrrolate $(0.01 \mathrm{mg} / \mathrm{kg})$, and the extubation was performed when criteria for extubation were fulfilled. Haemodynamics were monitored at extubation time $0,5,10 \mathrm{~min}$. also to evaluate the pregabalin premedication effect in different doses on pressor response during extubation. All patients were followed up properly for any side effects attributed particularly to study drug such as nausea, vomiting, any respiratory inadequacy or haemodynamic instability in form of hypotension/hypertension or tachycardia/bradycardia and managed that time only.

According to the study done by Rastogi et al,(9) their initial pilot observation indicated that approximately $20-23$ patients should be taken in each group so as to ensure a power of 0.80 for detecting clinically significant reduction of $10-20 \%$ in heart rate and mean arterial pressure. Assuming the 5\% dropout rate, final sample size was taken as 30 in each group, which would allow a type I error= 0.05 and type II error= 0.2 . All parameters are expressed as mean value \pm standard deviation. Statistical analysis was done with SPSS version 21.0 and data analysis was done with ANOVA, independent T and Chi square test.

\section{RESULTS}

90 consented patients were enrolled into the study and were segregated into 3 equal groups and were properly evaluated and compared. Table 1 depicts the demographic profile in sense of age and weight and duration of laryngoscopy and surgery in 3 groups. No significant difference was found between 3 groups with respect to age, weight, duration of laryngoscopy and duration of surgery. All patients were female, surgery was same i.e. MRM for CA Breast and the duration between oral premedication to induction of anaesthesia were same in 3 groups.

\begin{tabular}{|c|c|c|c|c|c|c|}
\hline Parameters & Group I & Group II & Group III & P Value & & \\
\hline & & & & I/II & I/III & II/III \\
\hline Age & $54.62 \pm 5.60$ & $53.60 \pm 6.24$ & $54.04 \pm 5.24$ & 0.5078 & 0.6802 & 0.7685 \\
\hline Weight & $64.48 \pm 4.14$ & $63.42 \pm 5.22$ & $64.32 \pm 5.04$ & 0.3871 & 0.8936 & 0.4996 \\
\hline \begin{tabular}{|l} 
Duration of laryngoscopy (seconds) \\
\end{tabular} & $9.34 \pm 0.90$ & $9.32 \pm 0.94$ & $9.40 \pm 0.74$ & 0.9332 & 0.7789 & 0.7155 \\
\hline Duration of surgery (minutes) & $120.00 \pm 10.32$ & $119.40 \pm 14.80$ & $120.00 \pm 12.24$ & 0.8561 & 1.000 & 0.8647 \\
\hline
\end{tabular}

The preoperative sedation score was compared by using Ramsay sedation scale and found that sedation was significantly higher in group II and III than group I. The group III patients (pregabalin $300 \mathrm{mg}$ ) had significantly higher sedation score than group II (pregabalin $150 \mathrm{mg}$ ) as depicted in Table 2.

\begin{tabular}{|c|c|c|c|c|c|c|}
\hline Sedation Score & Group I & Group II & Group III & P value & & I/III \\
\hline & & & & II/III \\
\hline Mean \pm S.D. & $2.24 \pm 0.54$ & $3.46 \pm 0.72$ & $4.02 \pm 0.32$ & 0.0001 & 0.0001 & 0.0003 \\
\hline
\end{tabular}

There was no significant difference in baseline and before induction heart rate among 3 groups. The heart rate increased maximally immediately with intubation ( 0 min.) in all the 3 groups, but this increase was significantly high in group I than group II and III. The heart rate remained significantly higher in group I than other 2 groups even at 5 min. and 10 min. too. No significant difference in increase of heart rate was found in group II and III (Table 3). Though the increase in heart rate as a pressor response to intubation was blunted by pregabalin $150 \mathrm{mg}$ and $300 \mathrm{mg}$, no statistically significant difference in this respect was found between 2 different doses of pregabalin i.e. $150 \mathrm{mg}$ and $300 \mathrm{mg}$ at $0,5,10 \mathrm{~min}$. 


\begin{tabular}{|c|c|c|c|c|c|c|}
\hline Time & Group I & Group II & Group III & P value & & I/III \\
\hline & & & & I/II & IIII \\
\hline Baseline & $84.62 \pm 8.46$ & $86.48 \pm 7.34$ & $85.82 \pm 7.32$ & 0.3668 & 0.5591 & 0.7286 \\
\hline Before induction & $82.68 \pm 7.46$ & $82.46 \pm 6.42$ & $83.28 \pm 7.48$ & 0.9030 & 0.6723 & 0.6504 \\
\hline 0 Min. & $108.52 \pm 6.22$ & $94.62 \pm 7.24$ & $90.68 \pm 7.20$ & 0.0001 & 0.0001 & 0.0389 \\
\hline 5 Min. & $104.48 \pm 7.16$ & $90.44 \pm 6.42$ & $86.43 \pm 6.28$ & 0.0001 & 0.0001 & 0.0175 \\
\hline 10 Min. & $96.24 \pm 6.42$ & $87.54 \pm 5.16$ & $85.72 \pm 7.28$ & 0.0001 & 0.0001 & 0.2685 \\
\hline \multicolumn{7}{|c|}{ Table 3. Change in Heart Rate (beats/min.) During Intubation } \\
\hline
\end{tabular}

There was no significant difference in baseline and before induction mean arterial pressure among 3 groups. The mean arterial pressure increased maximally immediately with intubation ( $0 \mathrm{~min}$.) in all the 3 groups but this increase was significantly high in group I than group II and III at 0, 5, $10 \mathrm{~min}$. No significant difference in increase of mean arterial pressure was found in group II and III (Table 4). The increase in mean arterial pressure as a pressor response to intubation was blunted by pregabalin $150 \mathrm{mg}$ and $300 \mathrm{mg}$ but was not completely stopped. However, no statistically significant difference in this respect was found between 2 different doses of pregabalin i.e. $150 \mathrm{mg}$ and $300 \mathrm{mg}$ at $0,5,10 \mathrm{~min}$.

\begin{tabular}{|c|c|c|c|c|c|c|}
\hline Time & Group I & Group II & Group III & $P$ value & & \\
\hline & & & & I/II & I/III & II/III \\
\hline Baseline & $84.74 \pm 6.28$ & $83.68 \pm 7.16$ & $84.18 \pm 7.04$ & 0.5445 & 0.7463 & 0.7860 \\
\hline Before induction & $81.94 \pm 7.46$ & $81.56 \pm 6.62$ & $81.02 \pm 8.84$ & 0.8350 & 0.6647 & 0.7898 \\
\hline 0 Min. & $94.56 \pm 6.42$ & $88.44 \pm 7.18$ & $85.64 \pm 6.11$ & 0.001 & 0.0001 & 0.1092 \\
\hline 5 Min. & $90.24 \pm 7.16$ & $84.60 \pm 6.84$ & $83.62 \pm 7.42$ & 0.0028 & 0.0009 & 0.5968 \\
\hline 10 Min. & $86.68 \pm 5.40$ & $82.14 \pm 5.46$ & $81.06 \pm 5.04$ & 0.0020 & 0.0001 & 0.4292 \\
\hline \multicolumn{7}{|c|}{ Table 4. Change in Mean Arterial Pressure ( $\mathrm{mmHg}$ ) During Intubation } \\
\hline
\end{tabular}

There was no significant difference in before extubation heart rate among 3 groups. The heart rate increased maximally immediately with extubation ( 0 min.) in all the 3 groups but this increase was significantly high in group I than group II and III. The heart rate remained significantly higher in group I than other 2 groups even at $5 \mathrm{~min}$. and $10 \mathrm{~min}$. too. No significant difference in increase of heart rate was found in group II and III (Table 5). Though the increase in heart rate as a pressor response to extubation was blunted by pregabalin $150 \mathrm{mg}$ and $300 \mathrm{mg}$ it was not completely stopped. No statistically significant difference in this respect was found between 2 different doses of pregabalin i.e. $150 \mathrm{mg}$ and $300 \mathrm{mg}$ at 0, 5, $10 \mathrm{~min}$.

\begin{tabular}{|c|c|c|c|c|c|c|}
\hline Time & Group I & Group II & Group III & P value & & \\
\hline & & & & I/II & I/III & II/III \\
\hline Before extubation & $86.24 \pm 6.14$ & $85.36 \pm 5.46$ & $85.28 \pm 5.84$ & 0.5597 & 0.5373 & 0.9565 \\
\hline 0 Min. & $104.80 \pm 5.88$ & $96.44 \pm 6.22$ & $92.28 \pm 7.40$ & 0.0001 & 0.0001 & 0.0218 \\
\hline 5 Min. & $98.28 \pm 6.42$ & $90.16 \pm 6.28$ & $88.22 \pm 5.42$ & 0.0001 & 0.0001 & 0.2053 \\
\hline 10 Min. & $93.42 \pm 6.28$ & $88.28 \pm 5.24$ & $86.62 \pm 5.16$ & 0.0011 & 0.0001 & 0.2213 \\
\hline \multicolumn{7}{|c|}{ Table 5. Change in Heart Rate (beats/min.) During Extubation } \\
\hline
\end{tabular}

There was no significant difference in before extubation mean arterial pressure among 3 groups. The mean arterial pressure increased maximally immediately with extubation $(0 \mathrm{~min}$.) in all the 3 groups but this increase was significantly high in group I than group II and III at 0, 5, $10 \mathrm{~min}$. No significant difference in increase of mean arterial pressure was found in group II and III (Table 6). Thus, the increase in mean arterial pressure as a pressor response to extubation was blunted by pregabalin premedication of $150 \mathrm{mg}$ and $300 \mathrm{mg}$ but was not completely stopped. However, no statistically significant difference in this respect was found between 2 different doses of pregabalin i.e. $150 \mathrm{mg}$ and $300 \mathrm{mg}$ at 0, 5, $10 \mathrm{~min}$.

\begin{tabular}{|c|c|c|c|c|c|c|}
\hline Time & Group I & Group II & Group III & P value & & \\
\hline & & & & I/II & I/III & II/III \\
\hline Before Extubation & $83.64 \pm 6.42$ & $82.16 \pm 7.40$ & $82.22 \pm 5.62$ & 0.4114 & 0.3658 & 0.9719 \\
\hline 0 Min. & $98.62 \pm 6.16$ & $90.14 \pm 6.40$ & $88.16 \pm 7.42$ & 0.0001 & 0.0001 & 0.2730 \\
\hline 5 Min. & $92.84 \pm 6.46$ & $86.28 \pm 5.48$ & $85.62 \pm 5.46$ & 0.0001 & 0.0001 & 0.6420 \\
\hline 10 Min. & $89.16 \pm 6.18$ & $84.04 \pm 5.82$ & $83.42 \pm 5.16$ & 0.0016 & 0.0002 & 0.6640 \\
\hline \multicolumn{7}{|c|}{ Table 6. Change in Mean Arterial Pressure $(\mathrm{mmHg})$ During Extubation } \\
\hline
\end{tabular}

In our study, Inj. Fentanyl $2 \mu \mathrm{g} / \mathrm{kg}$ was given to all patients. Inj. Propofol infusion 50-70 microgram $/ \mathrm{kg} / \mathrm{min}$. was given according to patient haemodynamics and thus, individualised. This infusion was stopped 10 min. before planned extubation. Postoperatively, VAS score was measured in recovery room immediately and followed up to 9 hrs. Immediate postoperative VAS score was significantly higher in group I than group II and III. Also group II patients showed significantly higher VAS score than group III (Table 7). Postoperative rescue analgesia was given with inj. Tramadol $50 \mathrm{mg}$ and when compared on followup, group I patients required rescue analgesia earlier than group II and III patients. Group III patients remained pain free significantly for a longer period than group II patients (Table 8). Side effects such as headache, dizziness, confusion, ataxia have been reported in literature attributed to pregabalin. In our study, only 1 patient in group III (Pregabalin $300 \mathrm{mg}$ ) had dizziness which was statistically insignificant. 


\begin{tabular}{|c|c|c|c|c|c|c|}
\hline Vas Score & Group I & Group II & Group III & P value & & \\
\hline & & & & I/II & I/III & II/III \\
\hline Mean \pm S.D. & $7.42 \pm 1.04$ & $3.46 \pm 1.28$ & $1.24 \pm 0.90$ & 0.0001 & 0.0001 & 0.0001 \\
\hline \multicolumn{7}{|c|}{ Table 7. Immediate Postoperative Visual Analogue Score (0-10) } \\
\hline
\end{tabular}

\begin{tabular}{|c|c|c|c|c|c|c|}
\hline Time (Min) & Group I & Group II & Group III & P value & & I/II \\
\hline & & & & I/III & III \\
\hline Mean \pm S.D. & $160.24 \pm 64.46$ & $308.46 \pm 72.26$ & $460.04 \pm 52.82$ & 0.0001 & 0.0001 & 0.0001 \\
\hline \multicolumn{7}{|c|}{ Table 8. Time for Rescue Analgesia (Postoperative Period) During Followup } \\
\hline
\end{tabular}

\section{DISCUSSION}

Our study was done to evaluate the 2 different doses of oral pregabalin (150 $\mathrm{mg}$ and $300 \mathrm{mg}$ ) as premedication for blunting the haemodynamic response to intubation and extubation in CA Breast patients undergoing Modified Radical Mastectomy procedure. These haemodynamic changes can be well tolerated by normal adult patients without any comorbid conditions but patients already having CA breast are compromised in a number of ways like undergoing radiation therapy, compromised immune response, hypertension, diabetes, advanced age and other comorbid conditions. Thus, these changes in haemodynamics during intubation and extubation may range from tachycardia and hypertension to significant arrhythmias, myocardial ischaemia, cerebrovascular accidents, etc. Thus, the blunting of this haemodynamic pressor response is of utmost importance in MRM patients. Many drugs have been used and evaluated to blunt this haemodynamic response either as premedication or induction drug such as vasodilators, adrenoceptor blocker, calcium channel blockers and opioids.[2,3]

In our study, we reported that there was significant increase in heart rate and mean arterial pressure in response to intubation and extubation in all the three groups. The same result was found by Shribman et al[10] that during laryngoscopy and intubation there is increase in heart rate, arterial blood pressure and catecholamine levels. Hassan et al[11] also reported same haemodynamic changes along with high incidences of cardiac arrhythmias, myocardial ischaemia, acute left ventricular failure and cerebrovascular accidents following intubation especially in hypertensive patients. In our study, significant blunting of haemodynamic response (Heart rate and mean arterial pressure) during and after intubation and extubation was seen in patients who received oral pregabalin as premedication in 2 different doses i.e. $150 \mathrm{mg}$ and $300 \mathrm{mg}$ as compared to control group, but there was no significant difference in this blunting between 2 doses of pregabalin. The same result was observed by Sundar et al[12] who evaluated the single dose of $150 \mathrm{mg}$ oral pregabalin as premedication vs. placebo for attenuation of pressor response to intubation in patients undergoing off pump coronary artery bypass grafting. Our results are in accordance with studies done by Rastogi et $\mathrm{al}^{9}$ and Eren et al.[13] The mechanism of action of pregabalin in this respect is still unknown but some postulate the inhibition of membrane dependent calcium channels (Memis et al).[14]

In our study, we found that preoperative sedation was significantly high in both pregabalin groups than control group and patients who received $300 \mathrm{mg}$ pregabalin were significantly more sedated than patients who received 150 mg. Same results were established by White et al[15] who found that increased perioperative sedation in dose related manner of pregabalin premedication $(75,150,300 \mathrm{mg})$. We studied analgesic property of pregabalin at different doses too and conclude that immediate postoperative VAS score was significantly better in pregabalin groups than control group. Pregabalin $300 \mathrm{mg}$ produced significantly better analgesia than $150 \mathrm{mg}$ pregabalin. All patients were followed up to the time for need of rescue analgesia i.e. tramadol inj. $50 \mathrm{mg}$ and it was found that the time for need of rescue analgesia was significantly more in pregabalin groups than control group and significant difference was found between 2 doses of pregabalin in this respect. These findings are in accordance to Jokela et al,[16] Sarawat et al,[17] Peng et al,18 Patricia et al,[19] Burke et al,[20] Kim et al.[21] They all reported the good analgesic property of pregabalin. Various mechanisms may contribute to pregabalin analgesic property such as the modulation of visceral pain and central sensitisation. ${ }^{[5,6]}$ No significant side effects were reported in any of the groups.

Thus, the blunting of pressor response to intubation and extubation is of utmost importance in patients undergoing MRM for CA breast and pregabalin as a premedication in different doses not only blunt this response but also gives good postoperative analgesia in dose related manner without any significant postoperative side effects.

The main limitation of our study was the small sample size and further studies having bigger sample size is needed for same.

\section{CONCLUSION}

Oral pregabalin is not only effective but also a safe drug to be used as a premedication either in dose of $150 \mathrm{mg}$ or $300 \mathrm{mg}$ for attenuation of haemodynamic response to intubation and extubation. Pregabalin $300 \mathrm{mg}$ is better than $150 \mathrm{mg}$ in terms of good preoperative sedation and longer postoperative analgesia.

\section{REFERENCES}

[1] Prys-Roberts C, Green LT, Meloche R, et al. Studies of Anaesthesia in relation to hypertension. II. Hemodynamic consequences of induction and endotracheal intubation. Br J Anaesth 1971;43(6): 531-47.

[2] Korpien R, Sarnivaara L, Siren K, et al. Modification of the haemodynamic responses to induction of anaesthesia and tracheal intubation with alfentanil, esmolol and their combination. Can J Anaesth 1995;42(4):298-304.

[3] Helfman SM, Gold MI, DeLisser EA, et al. Which drug prevents tachycardia and hypertension associated with tracheal intubation: lidocaine, fentanyl or esmolol? Anesth Analg 1991;72(4):482-6. 
[4] Jokela R, Ahonen J, Tallgren M, et al. Premedication with pregabalin 75 or $150 \mathrm{mg}$ with ibuprofen to control pain after day-case gynaecological laparoscopic surgery. Br J Anaesth 2008;100(6):83440.

[5] Ben-Menachem E. Pregabalin pharmacology and its relevance to clinical practice. Epilepsia 2004;45(Suppl 6):13-8

[6] Stawicki SP. Sedation scales: very useful, very underused. OPUS 12 Scientist 2007;1:10-2.

[7] Miller RD. Miller's anaesthesia. Vol. 27. 7th edn. Philadelphia: Churchill Livingstone/Elsevier 2009.

[8] Magorian T, Flannery KB, Miller RD. Comparison of rocuronium, succinylcholine and vecuronium for rapid-sequence induction of anesthesia in adult patients. Anesthesiology 1993;79(5):913-8.

[9] Rastogi B, Gupta K, Gupta PK, et al. Oral pregabalin premedication for attenuation of hemodynamic pressor response of airway instrumentation during general anaesthesia: A dose response study. Indian J Anaesth 2012;56(1):49-54.

[10] Shribman AJ, Smith G, Achola KJ. Cardiovascular and catecholamine response to laryngoscopy with and without tracheal intubation. Br J Anaesth 1987;59(3): 295-9.

[11] Hassan HG, El-Sharkawy TY, Renck H, et al. hemodynamic and catecholamine stress responses to laryngoscopy with vs without endotracheal intubation. Acta Anesthesiol Scand 1991;35(5):442-7.

[12] Sundar AS, Kodali R, Sulaiman S, et al. The effects of preemptive pregabalin on attenuation of stress response to endotracheal intubation and opioidsparing effect in patients undergoing off-pump coronary artery bypass grafting. Ann Card Anaesth 2012;15(1):18-25.
[13] Eren G, Kozanhan B, Hergunsel 0, et al. Pregabalin blunts cardiovascular response to laryngoscopy and tracheal intubation. J Anesthesiol Reanimation 2008;7(2):82-7.

[14] Memis D, Turan A, Karamanlioglu B, et al. Gabapentin reduces cardiovascular responses to laryngoscopy and tracheal intubation. Eur J Anaesth 2006;23(8):686-90.

[15] White PF, Tufanogullari B, Taylor J, et al. The effect of pregabalin on preoperative anxiety and sedation levels: a dose-ranging study. Anaesth Analg 2009;108(4):1140-5.

[16] Jokela R, Ahonen J, Tallgren M, et al. A randomized controlled trial of preoperative administration of pregabalin for pain after laparoscopic hysterectomy. Pain 2008;134(1-2):106-12.

[17] Sarawat V, Arora V. Preemptive gabapentin vs pregabalin for acute postoperative pain after surgery under spinal anaesthesia. IJA 2008;52(6):829-34.

[18] Peng PW, Li C, Farcas E, et al. Use of low-dose pregabalin in patients undergoing laparoscopic cholecystectomy. Br J Anaesth 2010;105(2):155-61.

[19] Lavand'homme PM, Roelants F. Evaluation of pregabalin as adjuvant to patient controlled epidural analgesia during late termination of pregnancy. Anaesthiology 2010;113(5):1186-91.

[20] Burke SM, Shorten GD. Perioperative pregabalin improves pain and functional outcome 3 months after lumbar discectomy. Anesthsia \& Analgesia 2010;110(4):1180-5.

[21] Kim SY, Song JW, Park B, et al. Pregabalin reduces post-operative pain after mastectomy: a double-blind, randomized, placebo controlled study. Acta Anaesth Scandinavica 2011;55(3):290-6. 